\title{
GROWTH AND PROPERTIES OF DIAMOND FILMS PREPARED ON 4-INCH SUBSTRATES BY CAVITY PLASMA SYSTEMS
}

\author{
1,2Oleg BABČENKO, 1,2̌̌těpán POTOCKÝ, 'Kateřina AUBRECHTOVÁ DRAGOUNOVÁ, \\ ${ }^{1}$ Ondrej SZABÓ, ${ }^{3}$ Philippe BERGONZO, ${ }^{2}$ Bohuslav REZEK, ${ }^{1}$ Alexander KROMKA \\ 1'Institute of Physics of the Czech Academy of Sciences, Prague, Czech Republic, EU, babcenko@fzu.cz \\ ${ }^{2}$ Faculty of Electrical Engineering, Czech Technical University in Prague, Czech Republic, EU \\ ${ }^{3}$ Seki Diamond Systems, CORNES Technologies USA, San Jose, USA
}

https://doi.org/10.37904/nanocon.2020.3701

\begin{abstract}
Diamond attracts the interest of researchers from different fields due to its extraordinary properties. However, many applications demand diamond films over large areas hence limiting usage of natural diamonds. Here we compare two microwave $(2.45 \mathrm{GHz})$ plasma systems with ellipsoidal and multimode clamshell cavity for diamond synthesis by chemical vapor deposition. We use $\mathrm{H}_{2} / \mathrm{CH}_{4} / \mathrm{CO}_{2}$ gas mixture for diamond film deposition on $\mathrm{Si}<100>$ wafers. Both systems are capable of high pressure (up to $20 \mathrm{kPa}$ ) operation and high growth rates (several $\mu \mathrm{m} / \mathrm{h}$ ). We compare the cavity systems from the point of diamond quality (Raman shift measurement), substrate size (2" versus 4") and grown film homogeneity together with surface morphology (SEM), deposition rate and parasitic doping levels (photoluminescence). For instance, we show that by using the multimode operation of the clamshell cavity system and specially design sample holder, it is possible to sustain a plasma in a cavity and reach good enough process reproducibility and diamond film quality over 4 -inch substrates. We discuss effects of the cavity design on deposited layers for large area applications of diamond such as thermal management, electrodes and sensor arrays fabrication, photoluminescence, photonics and light sources.
\end{abstract}

Keywords: Large area diamond, microwave cavity plasma, high-power density plasma

\section{INTRODUCTION}

Diamond is a material with a wide range of extraordinary properties. It is the hardest natural material with the highest bulk thermal conductivity, broad optical transparency window and high resistance to chemical corrosion [1-3]. These properties would be enough to make a diamond an attractive material for various industrial applications. However, due to the high costs of natural diamonds proportional to size, the researchers had to develop synthetic diamond production methods [4-7]. Synthesis of diamond thin films was recognized as an appropriate alternative for various experimental needs [2-6]. Usage of synthetic diamond enabled discovery of other beneficial properties such as negative electron affinity, high radiation hardness, high breakdown field, biocompatibility, ability to form optical centers, adjustable electrical properties and surface chemistry, superconductivity with high boron doping levels, etc. [1-6]. It significantly expanded the list of diamond potential applications. Diamond films and coatings were thus proposed not only for cutting and drilling tools but also for heat spreaders and thermal management, optically transparent and electrically insulating encapsulation with high heat conductivity, high-power electronics, corrosion resistant electrodes, optoelectronic and quantum devices, various sensors or detectors and many more [1-6].

The diamond films are routinely grown by the chemical vapor deposition (CVD) method in various systems. The most popular are hot filament and microwave plasma reactors for which the fast growth rates (up to 10 $\mu \mathrm{m} / \mathrm{h}$ ) were reported [2-4, 7-9]. Characteristic features of such systems are hydrogen rich gas mixtures and high process temperatures that affect diamond growth kinetics. Although the diamond CVD is nowadays a 
well-established technology, the challenge is to grow diamond on large area with a fast growth rate and homogeneous properties. The hot filament CVD system can fulfill this demand via the filament length increase and/or new filaments addition. However, it is suffering from several significant limitations. The impurities from the filaments and/or its sensitivity to gas chemistry (in particular oxygen or high amount of methane) are not desirable or even prohibited in some cases, e.g. specific electronic devices, optical or photonic applications, etc. $[1-3,9]$. Therefore, the solution for applications that requires diamond deposition on an area from 3 to 5 inches is searched by modifications of microwave plasma reactors.

The microwave plasma reactors exist in several configurations and have high potential to optimize diamond CVD technology $[5,10]$. In the current work we compare two microwave $(2.45 \mathrm{GHz})$ cavity plasma CVD systems. The first system has a rotational ellipsoid cavity and the second one has a multimode clamshell cavity. Both systems are capable of high pressure (up to $20 \mathrm{kPa}$ ) and high power (up to $6 \mathrm{~kW}$ ) operation, high growth rates (several $\mu \mathrm{m} / \mathrm{h}$ ) and in standard configuration diamond deposition on 2-inch substrates with the possibility of doping by boron. Our study focused on fast and reproducible diamond growth using oxygen containing chemistry in both these systems. We compare the systems from the point of diamond quality (Raman shift measurement), substrate size (2" versus 4") and diamond film homogeneity together with surface morphology (SEM), deposition rate and parasitic doping levels (photoluminescence). We demonstrate the potential and discuss the effect of improvements in the system design for large area diamond deposition for such applications as thermal management, electrodes and sensor arrays fabrication, photoluminescence, photonics, light sources, etc.

\section{EXPERIMENT}

As substrates, 2" and 4" $\mathrm{Si}<100>$ wafers were used. In all cases the diamond nucleation layer was prepared by the substrate treatment in the ultrasound bath in water-based nanodiamond powder suspension (NanoAmando, with nominal particle size $5 \mathrm{~nm}$ ) for $40 \mathrm{~min}$, as a reliable and reproducible seeding technique $[6,11]$. The wafers were held in the PTFE holder that enables easy manipulation and minimizes the damage of the seeding layer. Growth of diamond thin films was realized in the rotational ellipsoid cavity (P6, Diamond Materials $\mathrm{GmbH}$ ) $[5,10,12]$ and multimode clamshell cavity (SDS6K, Seki Diamond Systems) [2,5,10] 2.45 $\mathrm{GHz}$ microwave (MW) plasma CVD systems.

In the first set of experiments the 2" Si substrates were used. Diamond deposition in the rotational ellipsoid cavity (REC) reactor (ellipsoidal cavity resonator with the quartz bell jar as process chamber) was realized at the pressure $10.7 \mathrm{kPa}$ (107 mbar), microwave power $6 \mathrm{~kW}$, gas flow $500 \mathrm{sccm}$ of $\mathrm{H}_{2}, 25 \mathrm{sccm}$ of $\mathrm{CH}_{4}$ and 5 $\mathrm{sccm}$ of $\mathrm{CO}_{2}$. The average deposition temperature during the process was $740{ }^{\circ} \mathrm{C}$. Process parameters for the multimode clamshell cavity (MCC) reactor, where the deposition chamber is a whole cavity itself, were the same: pressure $10.7 \mathrm{kPa}$ (80 Torr), microwave power $6 \mathrm{~kW}$, gas flow $500 \mathrm{sccm}$ of $\mathrm{H}_{2}, 25 \mathrm{sccm}$ of $\mathrm{CH}_{4}$ and 5 $\mathrm{sccm}$ of $\mathrm{CO}_{2}$. The average deposition temperature with advanced substrate holder cooling during the process was $890^{\circ} \mathrm{C}$. In both cases, prior to $\mathrm{CO}_{2}$ addition into the process gas mixture the diamond nucleation layer was stabilized in the mixture of hydrogen and methane.

The diamond thin film deposition on the large 4" Si wafers was realized in the MCC reactor under the following conditions: pressure $6.7 \mathrm{kPa}$ (50 Torr), microwave power $5 \mathrm{~kW}$, gas flow $1000 \mathrm{sccm}$ of $\mathrm{H}_{2}$ and $25 \mathrm{sccm}$ of $\mathrm{CH}_{4}$. The average temperature during the 3 hours deposition process was $840^{\circ} \mathrm{C}$. A special holder for large wafers was used without additional cooling.

After the deposition the surface morphology of diamond films was characterized by the field-emission scanning electron microscopy (FE-SEM, Tescan MAIA3). The growth rates were calculated from the mass of the layers deposited on the known area taking the diamond film density equal to $3,5 \mathrm{~g} / \mathrm{cm}^{3}[4,13]$. Material and photoluminescence properties were studied by the Raman spectroscopy (Renishaw InVia Reflex Raman microscope) using the excitation wavelength of $442 \mathrm{~nm}$. 


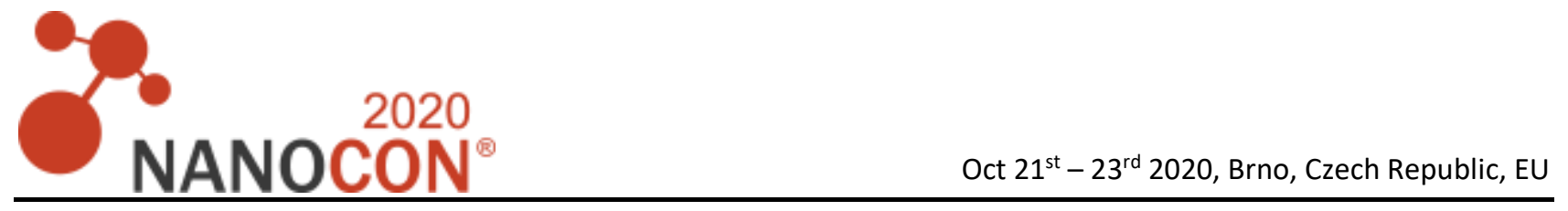

\section{RESULTS AND DISCUSSION}

\subsection{Deposition on the 2-inch substrates}

The CVD process using the $\mathrm{H}_{2} / \mathrm{CH}_{4} / \mathrm{CO}_{2}$ gas mixture in both systems resulted in optically uniform coating on the used 2" Si substrates. In order to identify the possible changes in the films homogeneity, morphology and more precisely evaluate the growth rate, the deposition processes were repeated several times with different duration. SEM images of the layers deposited in the two employed reactors using the same deposition process settings and time are shown in Figure 1 and Figure 2. The average size of diamond crystals for layer grown for $3 \mathrm{~h}$ in the REC reactor is in the range $1.0-1.5 \mu \mathrm{m}$, while layer grown during $9 \mathrm{~h}$ includes larger (up to 4 $\mu \mathrm{m}$ ) and smaller (around $1 \mu \mathrm{m}$ ) diamond crystals (Figure 1). In case of the MCC reactor, already the layer grown for $3 \mathrm{~h}$ demonstrates high distribution of diamond crystals (from 0.5 to $4 \mu \mathrm{m}$ ). Layers grown for longer time show increase of maximum grain size with up to $15 \mu \mathrm{m}$ large crystals (surrounded by smaller grains) observable on SEM images from $9 \mathrm{~h}$ deposited layer (Figure 2).
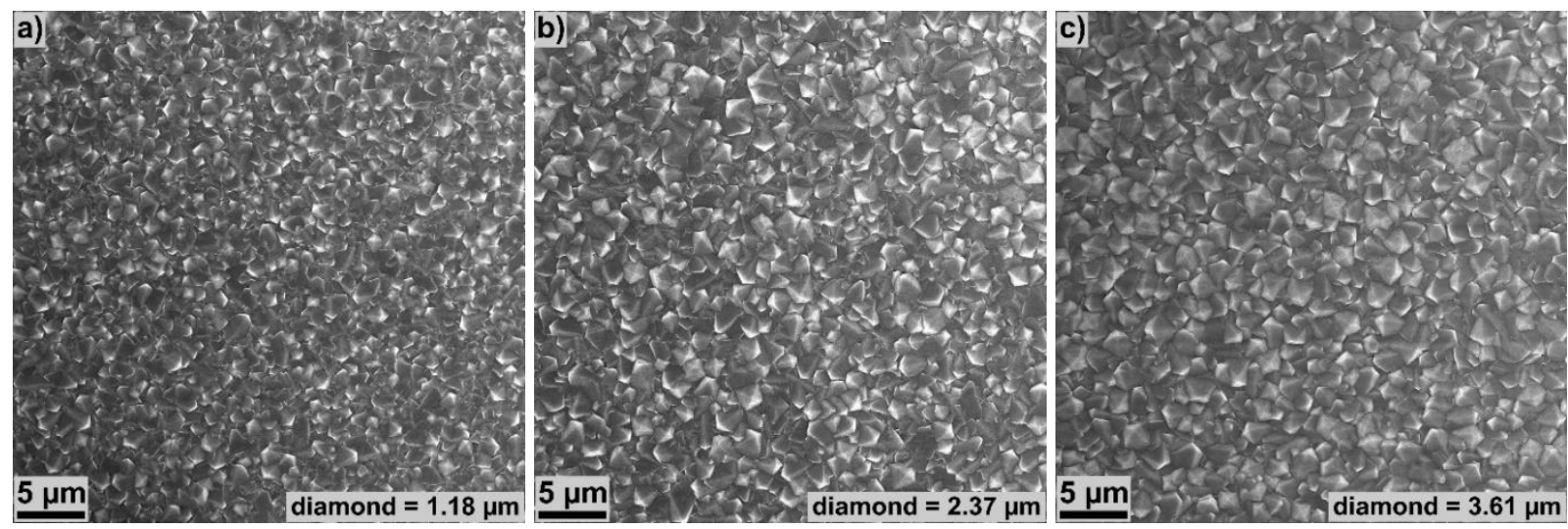

Figure 1 The SEM images of diamond films grown in the REC reactor for: a) $3 \mathrm{~h}, \mathrm{~b}) 6 \mathrm{~h}$, and c) $9 \mathrm{~h}$

In general, the crystal size of diamond layers is affected by the grown film thickness $[2,3,6]$. Indeed, the thickness (denoted as "diamond" in Figure 1 and Figure 2) that was calculated from the mass of layers deposited for the time from 3 to $9 \mathrm{~h}$ correlates with the morphology of diamond films investigated by the SEM. The estimated growth rates in case of REC reactor was around $0.39-0.40 \mu \mathrm{m} / \mathrm{h}$, while for MCC reactor this value was between $2.07-2.25 \mu \mathrm{m} / \mathrm{h}$. Commonly, to achieve by MW plasma CVD the thick diamond layers at high diamond growth rate the high-power density plasmas and thermally stable substrates (e.g. thick enough to sustain high temperature load) are used $[2-5,8,12]$. Nevertheless, as it can be seen from the comparison of the film thicknesses (and derived growth rates) and SEM images the diamond growth kinetics remained affected by the operation regime of the employed CVD system.
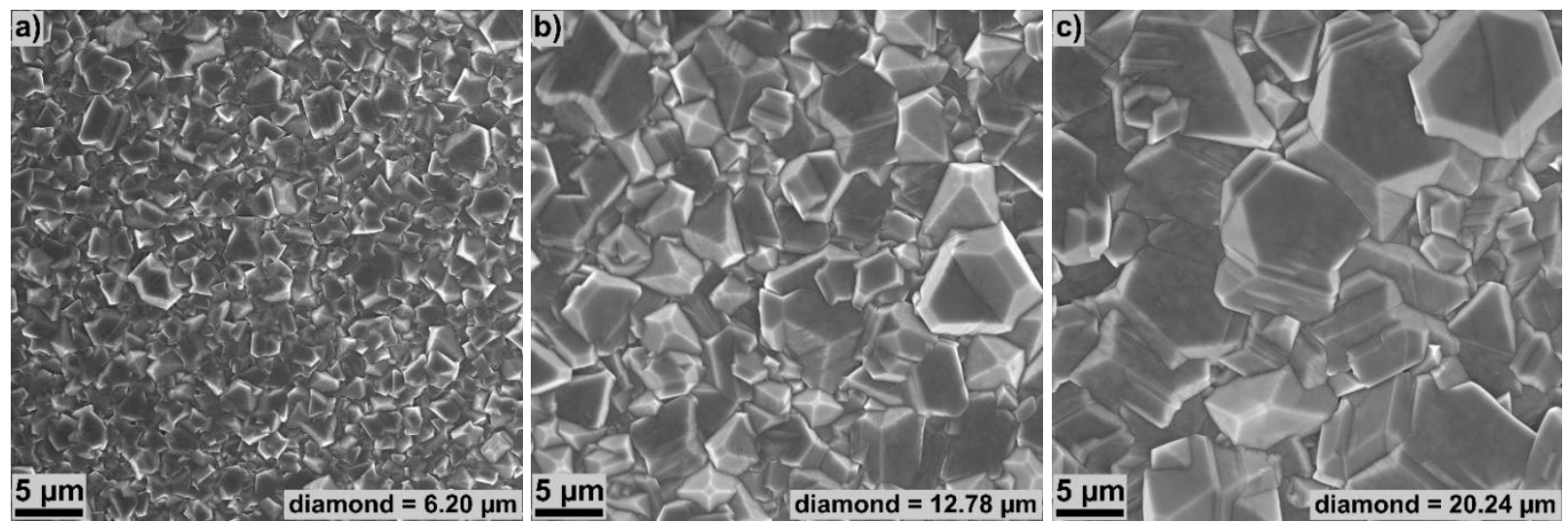

Figure 2 The SEM images of diamond film grown in the MCC reactor for: a) $3 \mathrm{~h}, \mathrm{~b}$ ) $6 \mathrm{~h}$, and c) $9 \mathrm{~h}$ 
The representative Raman spectra of the grown diamond films are shown in Figure 3. Raman spectroscopy in all cases indicates the high-quality diamond layer with a strong and sharp peak at $1332 \mathrm{~cm}^{-1}$, characteristic for microcrystalline diamond films [14,15]. Considering the above SEM morphology this finding was expected. Diamond films with crystals as large as $500 \mathrm{~nm}$ already demonstrate a negligible amount of graphitic phases $[14,15]$ whilst in the investigated cases, the size of diamond crystals is even larger. In agreement with previous reports, the second order Si peak from the substrate observable in the spectra of thinner diamond films grown in the REC reactor at around $980 \mathrm{~cm}^{-1}$ is diminishing with increasing diamond layer thickness [14,16]. However, the photoluminescence tail remains high even for thick films indicating "parasitic doping" due to plasma contact with quartz bell jar [5].
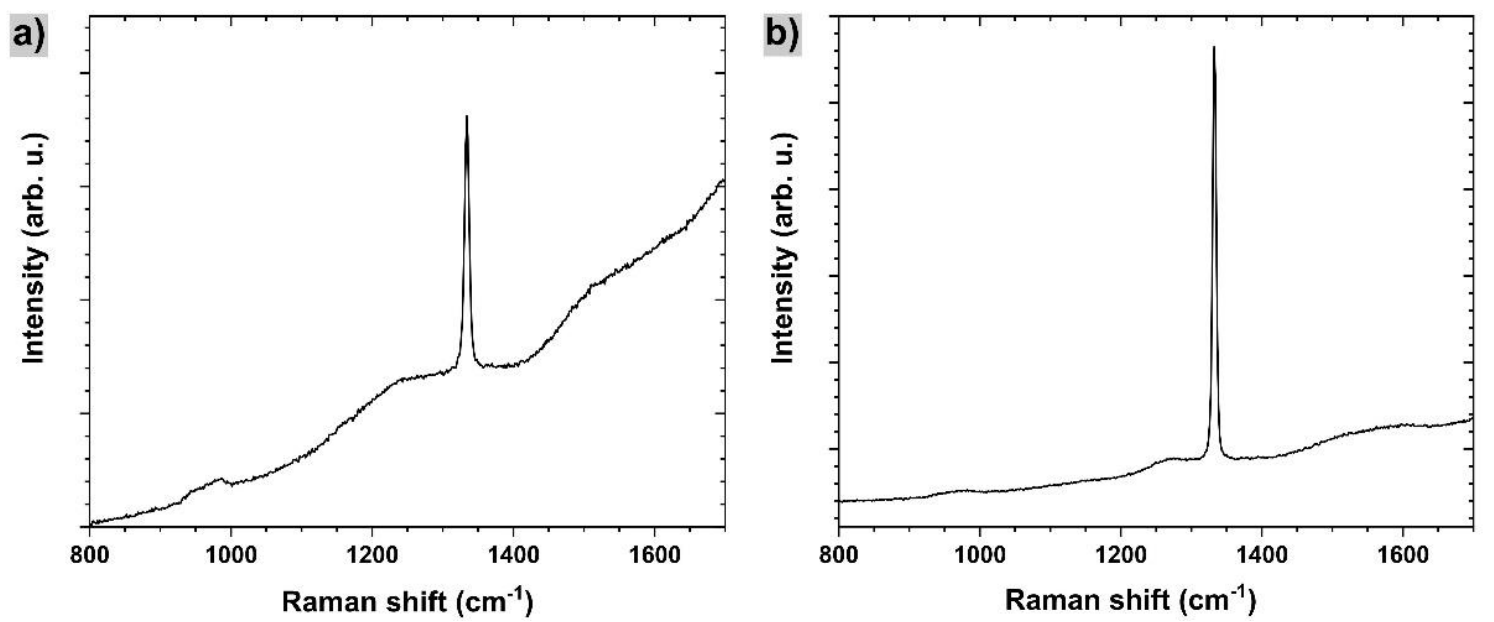

Figure 3 The Raman spectra measured after 3 h deposition on 2" Si in: a) REC reactor and b) MCC reactor

All aforementioned results indicate that the chosen deposition conditions are more suitable for the multimode clamshell cavity reactor than the rotational ellipsoid cavity reactor. Indeed, design of the REC reactor allows to maintain the stable plasma ball localized in the close vicinity to the substrate in the wide pressure range $[12,16]$. Therefore, the diamond deposition in the REC-reactor is realized in the round area with a diameter of approximately $5 \mathrm{~cm}$ while larger substrates can suffer from less homogeneous deposition $[10,12,16]$. However, at high power conditions the plasma discharge tends to be vertically expanded to the volume of the bell jar which decrease the plasma density and thus negatively affects the deposition temperature and growth rate $[10,12]$. Moreover, such expansion to the volume when plasma is approaching the quartz bell jar walls cause higher "parasitic doping" due to walls etching. The aforementioned issues can be overcome by the increase of deposition pressure that suppresses the plasma expanding and thus facilitate the growth rate [16].

Contrary to that, in the multimode clamshell cavity reactor operation at high power and lower deposition pressures cause more pronounced horizontal expansion of plasma discharge. Moreover, the pressure when such expansion becomes evident is lower than for the REC reactor $[5,10]$. The plasma expansion can be additionally altered by the design of the substrate holder. These properties of the MCC reactor were important in the research oriented at enlarging the deposition area and finally with specially designed substrate holder it became possible to expand the plasma discharge across the area of at least 4 " in diameter [2,10]. For comparison, the system with rotational ellipsoid cavity for deposition on large wafers requires system with MW generators of lower frequency $(915 \mathrm{MHz})$ and scaling up of resonator "egg" by factor of 2.7 [2,10,12]. It was reported that via employing large REC-type reactors and $915 \mathrm{MHz} / 60 \mathrm{~kW}$ generators the fast diamond deposition can be achieved on wafers up to 6 " in diameter $[2,10,12]$. Such experiments cannot be commonly realized as they require complete change of the CVD system. Therefore, the experiments on the 4" wafers were realized only in the MCC reactor by changing the process parameters. 


\subsection{Deposition on the 4-inch substrates}

The representative images of the expanded plasma discharge and the diamond film grown on 4" Si wafer for $3 \mathrm{~h}$ in the MCC reactor are shown in Figure 4. Visually, the thickness of diamond layer in this case seems to be not as high as in case of deposition on 2" substrates. Note also very few interference fringes seen due to diamond's high index of refraction. It indicates highly uniform film thickness as analyzed further below.
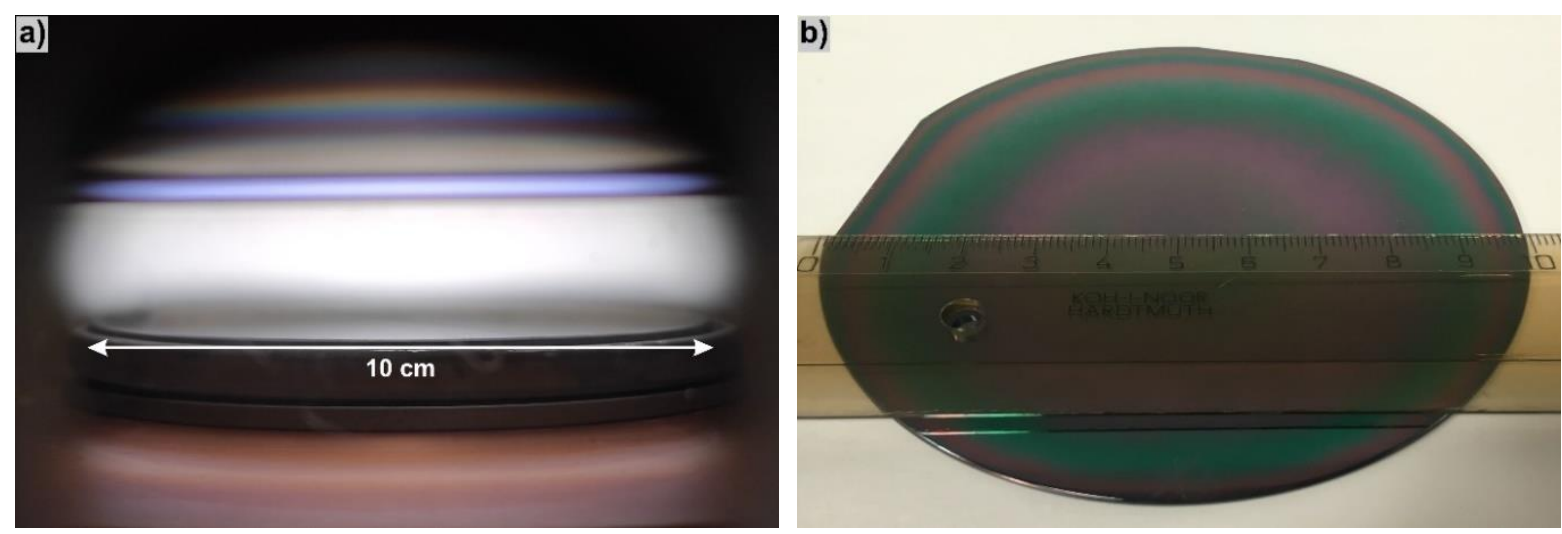

Figure 4 Photo of: a) plasma discharge in MCC reactor during the CVD and b) diamond film on the 4" $\mathrm{Si}$

The SEM demonstrates that the grown layer is pinholes-free and consists of densely packed fine-grained crystallites in size up to $1 \mu \mathrm{m}$ (Figure 5a). The Raman spectroscopy (Figure 5b), in addition to sharp diamond peak at $1332 \mathrm{~cm}^{-2}$, characteristic to microcrystalline diamond, also demonstrate the presence of graphitic phases (broad band from $1400 \mathrm{~cm}^{-1}$ to $1600 \mathrm{~cm}^{-1}$ ) and the second order Raman signal of Si substrate (band from $920 \mathrm{~cm}^{-1}$ to $1040 \mathrm{~cm}^{-1}$ ) [14,15]. Stronger graphitic phases and second order signal from Si in the spectrum is another indication of lower diamond film thickness comparing to layers grown on 2" samples. The photoluminescence tail in case of diamond films from MCC reactor is low due to low level of parasitic doping (plasma is at far distance from the chamber walls) [5,10]. An additional analysis done by interference spectroscopy identifies the diamond thickness variation from $400 \mathrm{~nm}$ to $500 \mathrm{~nm}$, i.e. the growth rate was significantly lower comparing to the deposition on 2" Si. The decrease of the growth rate is primarily related to the reduction of plasma density due to its expansion over the 4" sample (higher plasma volume) [10]. It should be noted that at lower applied power the plasma density is lower and the diamond thickness variation on large deposition areas became more evident [13]. Nevertheless, in our experiment the diamond growth was observed on the whole area of 4" Si wafer at the power of $5 \mathrm{~kW}$ and the quality remains close to the of MCC 2 " samples rather than to the REC samples. It should be mentioned, that optimized process conditions result in layer thickness homogeneity as high as $95 \%$.
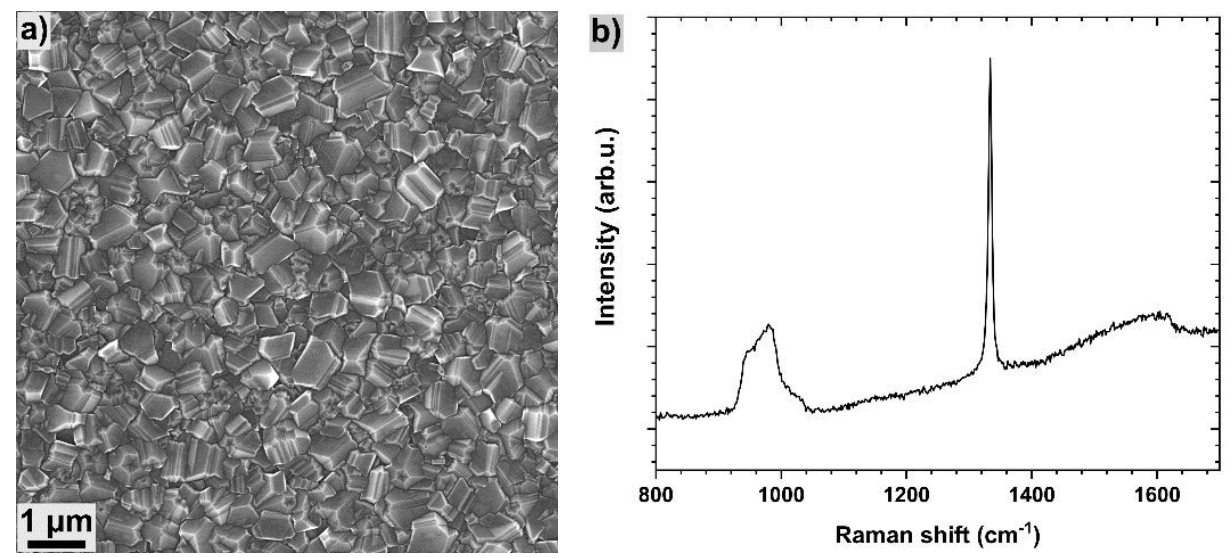

Figure 5 Diamond film grown on 4" Si wafer in the MCC reactor: a) SEM image and b) Raman spectrum 
Compared to the REC reactor, that for deposition on large wafers (>3") requires scaling up (by factor 2.7) of the system and high-power MW generators $(915 \mathrm{MHz} / 60 \mathrm{~kW})$ to maintain the stable plasma of sufficient density [2,10,12], simple change of substrate holder in MCC reactor for deposition on 4" wafers, although with slower growth rate, is much more convenient. Lower photoluminescence of diamond from the MCC reactor indicates also higher material purity and provides lower background for possible applications. Therefore, the MCC reactor is potentially attractive for research also on small samples and for large-scale application of diamond films, e.g. thermal management for high-power electronics, optical windows and other optical elements, large arrays of photonic structures or photoluminescence nanostructures and electrically insulating chemically resistant coatings. The possibility of controlled boron doping reported for this type of CVD systems $[4,8]$ enables fabrication of large area electrodes resistant to chemical corrosion, arrays of sensors or optoelectronic devices, etc.

\section{CONCLUSION}

We demonstrate the high diamond film growth rate by the high-power density plasma using two different deposition systems. We observe that despite the same $\mathrm{H}_{2} / \mathrm{CH}_{4} / \mathrm{CO}_{2}$ process gas mixtures and other deposition conditions were used the diamond films were grown in both system with different growth rates and homogeneity. It was explained by the difference of operation regimes characteristic for used facilities that affect the deposition temperature and diamond growth kinetics. While the design of ellipsoidal cavity resonator allows to maintain stable plasma ball in the quartz bell jar in a wide pressure range the design of multimode clamshell cavity reactor tolerates change of plasma discharge shape and allows to expand it when suitable substrate holder is used. We have shown that the reproducible diamond films synthesis is well achievable in the MCC reactor on the substrates as large as 4" in diameter. We propose that the MCC reactor is a promising system for large area diamond growth for thermal management, electrodes fabrication, photonic applications, photoluminescence studies, etc.

\section{ACKNOWLEDGEMENTS}

This work was supported by the Operational Programme Research, Development and Education financed by European Structural and Investment Funds and the MEYES project SOLID21 (no. CZ.02.1.01/0.0/0.0/16_019/0000760) and by the CzechNanolab research infrastructure (no. LM2018110). We gratefully acknowledge R. Yatskiv and P. Bauerová for technical support with SEM and Raman measurements.

\section{REFERENCES}

[1] DAVIS, Robert F. (ed.). Diamond films and coatings: development, properties, and applications. Park Ridge, N.J : Noyes Pub, 1993. Materials science and process technology series. ISBN 978-0-8155-1323-0. TP873.5.D5 D52 1993

[2] MAY, P. W. Diamond thin films: a 21st-century material. Philosophical Transactions of the Royal Society A: Mathematical, Physical and Engineering Sciences. [online]. 15 January 2000, vol. 358, no. 1766, pp. 473-495. Available from: https://doi.org/10.1098/rsta.2000.0542.

[3] GRACIO, J J, FAN, Q H and MADALENO, J C. Diamond growth by chemical vapour deposition. Journal of Physics D: Applied Physics. [online]. 22 September 2010, vol. 43, no. 37, pp. 374017. Available from: https://doi.org/10.1088/0022-3727/43/37/374017.

[4] BUTLER, James E. and SUMANT, Anirudha V. The CVD of Nanodiamond Materials. Chemical Vapor Deposition. [online]. July 2008, vol. 14, no. 7-8, pp. 145-160. Available from: https://doi.org/10.1002/cvde.200700037.

[5] WERNER, M and LOCHER, R. Growth and application of undoped and doped diamond films. Reports on Progress in Physics. [online]. 1 December 1998, vol. 61, no. 12, pp. 1665-1710. Available from: https://doi.org/10.1088/0034-4885/61/12/002. 
[6] WILLIAMS, O.A., NESLADEK, M., DAENEN, M., MiCHAELSON, S., HOFFMAN, A., OSAWA, E., HAENEN, K. and JACKMAN, R.B. Growth, electronic properties and applications of nanodiamond. Diamond and Related Materials. [online]. July 2008, vol. 17, no. 7-10, pp. 1080-1088. Available from:

https://doi.org/10.1016/j.diamond.2008.01.103.

[7] HIRMKE, J., SCHWARZ, S., ROTTMAIR, C., ROSIWAL, S.M. and SINGER, R.F. Diamond single crystal growth in hot filament CVD. Diamond and Related Materials. [online]. April 2006, vol. 15, no. 4-8, pp. 536-541. Available from: https://doi.org/10.1016/j.diamond.2006.01.003.

[8] SCHULTE, B., JUERGENSEN, H., BLACKBOROW, P. and SEVILLANO, E. Flexibility of microwave plasma chemical vapour deposition for diamond growth. Surface and Coatings Technology. [online]. October 1995, vol. 74-75, pp. 634-636. Available from: https://doi.org/10.1016/0257-8972(95)08311-1.

[9] MARTON, Marian, VOJS, Marian, KOTLÁR, Mário, MICHNIAK, Pavol, VANČO, L'ubomír, VESELÝ, Marian and REDHAMMER, Robert. Deposition of boron doped diamond and carbon nanomaterials on graphite foam electrodes. Applied Surface Science. [online]. September 2014, vol. 312, pp. 139-144. Available from: https://doi.org/10.1016/i.apsusc.2014.05.199.

[10] SILVA, F, HASSOUNI, K, BONNIN, X and GICQUEL, A. Microwave engineering of plasma-assisted CVD reactors for diamond deposition. Journal of Physics: Condensed Matter. [online]. 9 September 2009, vol. 21, no. 36, p. 364202. Available from: https://doi.org/10.1088/0953-8984/21/36/364202.

[11] KROMKA, A., BABCHENKO, O., KOZAK, H., HRUSKA, K., REZEK, B., LEDINSKY, M., POTMESIL, J., MICHALKA, M. and VANECEK, M. Seeding of polymer substrates for nanocrystalline diamond film growth. Diamond and Related Materials. [online]. May 2009, vol. 18, no. 5-8, pp. 734-739. Available from: https://doi.org/10.1016/j.diamond.2009.01.023.

[12] FÜNER, M., WILD, C. and KOIDL, P. Novel microwave plasma reactor for diamond synthesis. Applied Physics Letters. [online]. 9 March 1998, vol. 72, no. 10, pp. 1149-1151. Available from: https://doi.org/10.1063/1.120997.

[13] PHILIP, J., HESS, P., FEYGELSON, T., BUTLER, J. E., CHATTOPADHYAY, S., CHEN, K. H. and CHEN, L. C. Elastic, mechanical, and thermal properties of nanocrystalline diamond films. Journal of Applied Physics. [online]. 15 February 2003, vol. 93, no. 4, pp. 2164-2171. Available from: https://doi.org/10.1063/1.1537465.

[14] IŽÁK, Tibor, DOMONKOS, Mária, BABCHENKO, Oleg, VARGA, Marián, REZEK, Bohuslav, JURKA, Vlastimil, HRUŠKA, Karel and KROMKA, Alexander. Technological Aspects in Fabrication of Micro- and Nano-Sized Carbon Based Features: Nanorods, Periodical Arrays and Self-Standing Membranes. Journal of Electrical Engineering. [online]. 1 September 2015, vol. 66, no. 5, pp. 282-286. Available from: https://doi.org/10.2478/jee2015-0046.

[15] KLAUSER, Frederik, STEINMÜLLER-NETHL, Doris, KAINDL, Reinhard, BERTEL, Erminald and MEMMEL, Norbert. Raman Studies of Nano- and Ultra-nanocrystalline Diamond Films Grown by Hot-Filament CVD. Chemical Vapor Deposition. [online]. 9 June 2010, vol. 16, no. 4-6, pp. 127-135. Available from: https://doi.org/10.1002/cvde.200906827.

[16] MORTET, V., KROMKA, A., KRAVETS, R., ROSA, J., VORLICEK, V., ZEMEK, J. and VANECEK, M. Investigation of diamond growth at high pressure by microwave plasma chemical vapor deposition. Diamond and Related Materials. [online]. April 2004, vol. 13, no. 4-8, pp. 604-609. Available from: https://doi.org/10.1016/i.diamond.2003.11.034. 